Article

\title{
MODIS-Derived Spatiotemporal Changes of Major Lake Surface Areas in Arid Xinjiang, China, 2000-2014
}

\section{Qingting Li ${ }^{1}$, Linlin Lu ${ }^{1,2, *}$, Cuizhen Wang ${ }^{3}$, Yingkui Li $^{4}$, Yue Sui ${ }^{1}$ and Huadong Guo ${ }^{1}$}

1 Key Laboratory of Digital Earth Science, Institute of Remote Sensing and Digital Earth, Chinese Academy of Sciences, No. 9 Dengzhuang South Road, Haidian District, Beijing 100094, China; E-Mails: liqt@radi.ac.cn (Q.L.); yue11680@163.com (Y.S.); hdguo@radi.ac.cn (H.G.)

2 State Key Laboratory of Remote Sensing Science, Institute of Remote Sensing and Digital Earth, Chinese Academy of Sciences, Beijing 100101, China

3 Department of Geography, University of South Carolina, Columbia, SC 29208, USA; E-Mail: cwang@mailbox.sc.edu

4 Department of Geography, University of Tennessee, Knoxville, TN 37996, USA; E-Mail: yli32@utk.edu

* Author to whom correspondence should be addressed; E-Mail: lull@radi.ac.cn; Tel.: +86-10-82178102; Fax: +86-10-82178177.

Academic Editor: Miklas Scholz

Received: 20 August 2015 / Accepted: 8 October 2015 / Published: 21 October 2015

\begin{abstract}
Inland water bodies, which are critical freshwater resources for arid and semi-arid areas, are very sensitive to climate change and human disturbance. In this paper, we derived a time series of major lake surface areas across Xinjiang Uygur Autonomous Region (XUAR), China, based on an eight-day MODIS time series in $500 \mathrm{~m}$ resolution from 2000 to 2014. A classification approach based on water index and dynamic threshold selection was first developed to accommodate varied spectral features of water pixels at different temporal steps. The overall classification accuracy for a MODIS-derived water body is $97 \%$ compared to a water body derived using Landsat imagery. Then, monthly composites of water bodies were derived for the months of April, July, and September to identify seasonal patterns and inter-annual dynamics of 10 major lakes $\left(>100 \mathrm{~km}^{2}\right)$ in XUAR. Our results indicate that the changing trends of surface area of major lakes varied across the region. The surface areas of the Ebinur and Bosten Lakes showed a significant shrinking trend. The Ulungur-Jili Lake remained relatively stable during the entire period.
\end{abstract}


For mountain lakes, the Barkol Lake showed a decreasing trend in April and July, but the Sayram Lake showed a significant expanding trend in September. The four plateau lakes exhibited significant expanding trends in all three seasons except for Arkatag Lake in July. The shrinking of major lakes reflects severe anthropogenic impacts due to agricultural and industrial needs, in addition to the impact of climate change. The pattern of lake changes across the XUAR can provide insight into the impact of climate change and human activities on regional water resources in this arid and semi-arid region.

Keywords: water bodies; Xinjiang Uygur Autonomous Region (XUAR); MODIS time series

\section{Introduction}

Inland water bodies are important parts of the hydrosphere, serving as an essential source of freshwater for human consumption, agriculture, industry, and other uses. Due to climate change, uneven distribution of precipitation, and human activities, water resources show tremendous temporal variability worldwide [1]. Lakes and rivers are primary freshwater sources available to the local population and their livestock in arid and semi-arid areas [2,3]. Spatial dynamics and up-to-date information on surface water resources are essential for understanding water resource-related issues in these areas. Temporal water bodies that provide habitats for plant and animal communities in these areas have rarely been included in global datasets, such as the Global Lakes and Wetlands Database (GLWD) [4,5] and Vector Map Level 0 (VMAP0) [6].

With the capability of synoptic view and repeated coverage of the earth's surface, satellite remote sensing is an effective means of extracting water bodies across a variety of spatial and temporal scales. Due to their strong absorption in the near-infrared (NIR) spectrum, optical remote sensing platforms, such as Landsat [7,8], Advanced Spaceborne Thermal Emission and Reflection Radiometer (ASTER) [9,10], and Satellite Pour l'Observation de la Terre (SPOT) [11], have been used to map the area of the water body at various spatial resolutions. However, the high costs, narrow swath, and long revisit intervals of the medium- and high-resolution images limit their applications on monitoring the dynamics of lake systems across large spatial scales. Remote sensing data with high temporal resolution have the advantage of documenting detailed water area variation. Time series data from satellite sensors, such as the SPOT VEGETATION, Moderate Resolution Imaging Spectroradiometer (MODIS), and Advanced Very High Resolution Radiometer (AVHRR), have been applied to seasonal and inter-annual change detection of water bodies over large areas [12-16].

One of the common image processing methods for extracting water extent is based on a threshold of a water detection index. Spectral indexes, such as Normalized Difference Water Index (NDWI) [17], Modified Normalized Difference Water Index (MNDWI) [18], and Normalized Difference Pond Index (NDPI) [11], have been developed for water detection using remote sensing imagery. NDWI uses green band and near-infrared band to distinguish water from vegetation and soil [17]. In order to enhance the ability of water detection, especially for areas with built-up land in the background, the middle infrared band was integrated into MNDWI and NDPI instead of NIR band in NDWI [11,18]. Built-up areas and water bodies show discriminating spectral responses at the MODIS short-wavelength 
infrared (SWIR) band. A Combined Water Index (CWI) combining SWIR's and NDVI's ability to represent vegetation information was proposed for water body identification using MODIS data [19]. In addition, spectral reflectance of water shows spatiotemporal variability across different scenes and acquisition dates. Thus, delineating water bodies using a standard threshold may become problematic in large-area applications [20]. A strategy for threshold computation of different satellite images is needed.

The Xinjiang Uygur Autonomous Region (XUAR), with a widespread area of $1,660,000 \mathrm{~km}^{2}$, is the largest autonomous region in China. There are 113 lakes with an area of $>1 \mathrm{~km}^{2}$ in the XUAR. Many lakes are important wetlands for threatened species, five of which are designated as the National Nature Reserves of China [21]. The water levels of inland lakes in XUAR are influenced by the runoff of their inflowing rivers, and are sensitive to climate change and human activities altering the rivers' inflows [22]. It has been reported in past studies that the water extent has been shrinking in past decades, causing severe environmental problems, such as land desertification, salinization, vegetation degradation, water shortage, and biodiversity loss in this arid/semi-arid area [22].

Several studies have examined changes of lakes in the XUAR using satellite imagery, such as Landsat [22-24], SPOT VEGETATION [25], and MODIS [12,26] data. Landsat TM imagery has been used to interpret changes in area of inland lakes in Xinjiang over the period 1975-2007, but only selected lakes in spring and autumn seasons were analyzed [22]. Comparing with nationwide lake surveys undertaken in the 1960s-1980s, Ma et al. (2010) reported that 62 lakes vanished in the XUAR from the 1960s to 2000s; one of the completely dried lakes is the Lop Nur Lake with an original lake area of $5500 \mathrm{~km}^{2}$ [23]. Water extents were found to have decreased significantly due to anthropogenic impacts, such as agricultural water consumption and damming in this region [24]. The Ebinur Lake, the largest salt lake in the XUAR, exhibited a significant inter-annual and inter-seasonal variation based on SPOT VEGETATION data [25]. However, due to the large area of XUAR, previous studies have mainly focused on selected water bodies and annual or seasonal temporal intervals. The temporal fluctuations in surface area of major lakes were monitored with MODIS data in XUAR, but only inter-annual variations were analyzed $[12,26]$. The temporal and spatial dynamics of lake surface areas across XUAR are rarely documented in detail.

The purpose of this study is to examine the spatiotemporal variation of water bodies from 2000 to 2014 based on MODIS time series data. Detailed objectives include: (1) to develop an automatic approach to extract water bodies from MODIS data; (2) to generate a 15-year water body mask and document the changes of water extent; and (3) to examine the driving factors of the changes in major lakes in the XUAR.

\section{Study Area}

The XUAR is located in north-western China and encompasses the Altay Mountains, Junngar Basin, Tianshan Mountain, Tarim Basin, and Kunlun Mountains from north to south (Figure 1). It is an arid and semi-arid area with mean annual precipitation ranging between 100 and $200 \mathrm{~mm}$ [27]. Vast areas of the XUAR are covered by grassland and desert [28]. Forests are sparsely scattered within high mountains and along rivers. Oasis landscapes characterized by human settlements and agriculture lands are distributed within inland river deltas, alluvial-diluvial plains, and along the edges of diluvial-alluvial fans. 


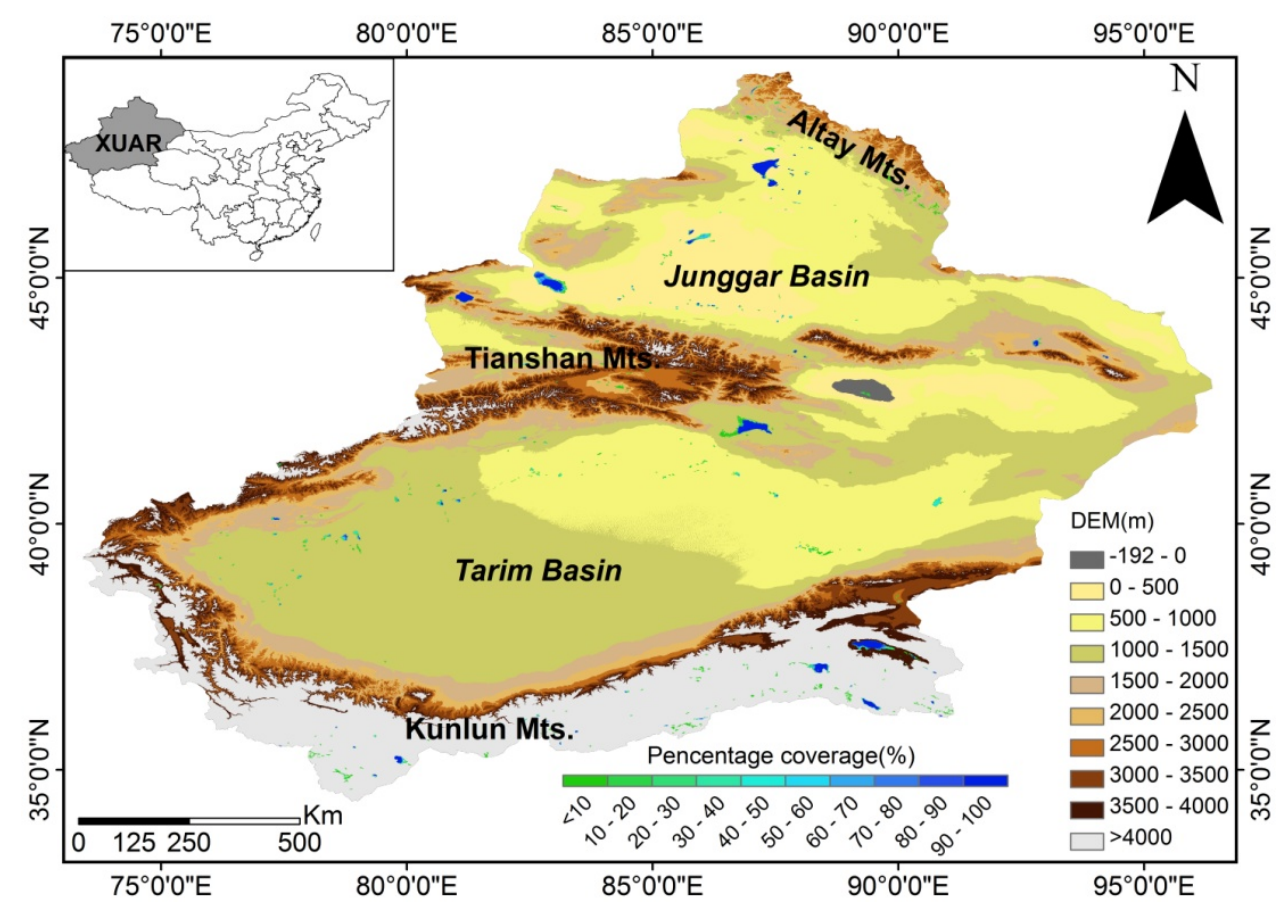

Figure 1. Geographic location and topographic map of study area. The percentage coverage of water bodies was combined for April, July, and September from 2000 to 2014.

According to the topographic characteristics, lakes in the XUAR can be categorized as four types [26]: (1) plateau lakes $(>3500 \mathrm{~m})$, with snow and glacier ice melt and surface runoffs as their main charge; (2) mountain lakes (1000-3500 m), with snow and glacier ice melt, underground runoff as their main influx; (3) plain lakes $(<1000 \mathrm{~m})$, heavily influenced by human activities; and (4) transition lakes, located at the transition area between mountains and plains.

Among all the lakes in the XUAR, 10 lakes have areas larger than $100 \mathrm{~km}^{2}$. Their total area accounts for more than $80 \%$ of the lake surface area (Table 1) [26].

Table 1. Ten major lakes in the study area (with surface area $>100 \mathrm{~km}^{2}$ ).

\begin{tabular}{cccccc}
\hline Name & $\begin{array}{c}\text { Area } \\
\left(\mathbf{k m}^{\mathbf{2}}\right.\end{array}$ & $\begin{array}{c}\text { Altitude } \\
(\mathbf{m})\end{array}$ & Mean Water Depth $(\mathbf{m})$ & Region & Type \\
\hline Ebinur & 673.46 & 194 & 1.2 & Junggar & Plain \\
Manas & 259.81 & 244 & 6 & Junggar & Plain \\
Ulungur-Jili & 1041.60 & 478 & 10.4 & Junggar & Plain \\
Bosten & 1004.33 & 1050 & 9 & Tarim & Transition \\
Sayram & 462.63 & 2072 & 46 & Junggar & Mountain \\
Barkol & 118.57 & 1577 & 0.6 & Junggar & Mountain \\
Ayakkum & 200.46 & 3876 & 10 & Kumukuli & Plateau \\
Aqqikkol & 168.93 & 4251 & 8 & Kumukuli & Plateau \\
Arkatag & 110.33 & 4713 & 8 & Kumukuli & Plateau \\
Aksayquin & 88.54 & 4844 & 8 & Northern Tibet & Plateau \\
\hline
\end{tabular}




\section{Materials and Methods}

\subsection{Remote Sensing Datasets}

Terra MODIS images were selected as the main data source for monitoring water body variation in XUAR. The MODIS Surface Reflectance (MOD09A1) dataset was used to build an image time series from 2000 to 2014 [29]. It provides surface reflectance at bands 1-7 with $500 \mathrm{~m}$ spatial resolution and eight-day temporal resolution. The XUAR region is entirely covered by six tiles (h23v04, h23v05, $\mathrm{h} 24 \mathrm{v} 04, \mathrm{~h} 24 \mathrm{v} 05, \mathrm{~h} 25 \mathrm{v} 04$, and h25v05). Lakes in XUAR were relatively stable during the spring and autumn seasons. In summer, some were influenced by extensive agricultural irrigation and high evaporation. In winter, some of the water bodies were frozen and may have caused high uncertainty in lake extent extraction. Therefore, we downloaded MODIS data for the months of April, July, and September to analyze the spatiotemporal dynamics of lake surface area. The Shuttle Radar Topography Mission (SRTM) digital elevation model with a spatial resolution of $90 \mathrm{~m}$ was used to correct the water body extraction affected by shadow and snow in mountainous regions [14,30].

Landsat data of $30 \mathrm{~m}$ resolution was used to assess the accuracy of remote sensing products with $250 \mathrm{~m} \mathrm{[31]} \mathrm{and} 1 \mathrm{~km}$ resolution [32]. In our study, Landsat TM, ETM+, and OLI images were used to validate the results of water extraction from MODIS data. A total of 71 Landsat image scenes (including Landsat $5 \mathrm{TM}$, Landsat $7 \mathrm{ETM}+$, and Landsat8 OLI_TIRS) were processed for the validation (Table 2).

Table 2. Landsat data used in our study.

\begin{tabular}{ccccc}
\hline Lake & Ulungur & Manas & Bosten & Ayakekumu \\
\hline \multirow{4}{*}{ Sensors } & Landsat5 TM & Landsat5 TM & Landsat5 TM & Landsat5 TM \\
& Landsat7 ETM+ & Landsat7 ETM+ & Landsat7 ETM+ & Landsat7 ETM+ \\
Landsat8 OLI_TIRS & Landsat8 OLI_TIRS & Landsat8 OLI_TIRS & Landsat8 OLI_TIRS \\
\hline Path/Row & 143/27, 144/27 & 144/28 & 143/31 & 140/34 \\
\hline 7 July 2000 & 16 March 2000 & 25 March 2000 & 4 September 2000 \\
& 24 September 2000 & 6 July 2000 & 31 July 2000 & 29 July 2001 \\
& 13 April 2001 & 24 September 2000 & 17 September 2000 & 1 October 2001 \\
27 July 2002 & 19 March 2001 & 1 August2006 & 11 April 2002 \\
& 14 September 2002 & 10 April 2003 & 10 September 2006 & 1 August2002 \\
& 10 April 2003 & 31 July 2006 & 14 April 2007 & 4 October 2002 \\
24 July 2006 & 17 September 2006 & 27 July 2007 & 14 April 2003 \\
& 17 September 2006 & 4 September 2007 & 13 September 2007 & 19 April 2005 \\
6 April 2007 & 23 July 2009 & 2 May 2008 & 27 July 2006 \\
23 July 2009 & 9 September 2009 & 16 July 2009 & 13 September 2006 \\
& 18 September 2009 & 10 May 2011 & 3 April 2009 & 6 July 2007 \\
10 May 2011 & 13 July 2011 & 6 July 2011 & 25 April 2010 \\
13 July 2011 & 1 October 2011 & 24 September 2011 & 30 July 2010 \\
& 13 April 2013 & 22 April 2013 & 31 August2010 \\
15 September 2011 & 2 July 2013 & 27 July 2013 & 8 May 2012 \\
13 April 2013 & 4 September 2013 & 29 September 2013 & 7 August2013 \\
11 July 2013 & 2 May 2014 & 31 August2014 & 24 September 2013 \\
29 September 2013 & 21 July 2014 & & 6 May 2014 \\
25 April 2014 & & &
\end{tabular}


The MODIS 500-m land-cover product (MCD12Q1) was used to identify primary land covers in the study area [33]. The MCD12Q1 is produced using an ensemble supervised classification algorithm with MODIS band 1-7 surface reflectance, an enhanced vegetation index, and land surface temperature as the main input. Post-processing refinements with ancillary datasets were also conducted. The MCD12Q1 product of 2012 covering the study area was downloaded. With the International Geosphere-Biosphere Program (IGBP) classification scheme, the land cover types were mapped and used to assess the impacts of human activities on lake changes in this study.

\subsection{MODIS-Based Water Body Extraction}

In XUAR, large areas of deserts and bare rocks have high spectral responses in short-wavelength infrared (SWIR) band [34]. Water usually has low reflectance along the spectrum. In this study we use CWI to detect water bodies from MODIS data. The computation formula of CWI is as follows [19]:

$$
\begin{gathered}
C W I=(N D V I+S W I R+\mathrm{A}) \times \mathrm{C} \\
N D V I=\frac{\mathrm{b} 2-\mathrm{b} 1}{\mathrm{~b} 2+\mathrm{b} 1} \\
S W I R=\frac{\mathrm{b} 7}{\overline{\mathrm{b} 7}},
\end{gathered}
$$

where b1, b2, and b7 represent the reflectance of band 1 (Red band, 620-670 nm), band 2 (NIR band, 871-876 nm), and band 7 (SWIR band, 2105-2155 nm) of the MOD09 data, respectively. A and C are correction factors to adjust the data ranges of $C W I$ values. They are empirically determined by comparing $C W I$ values between water pixels and background in the study area. We set $\mathrm{A}$ as 0.4 and $\mathrm{C}$ as 100 in our study [19]. Figure 2 illustrates the procedure for extracting water bodies based on MODIS data.

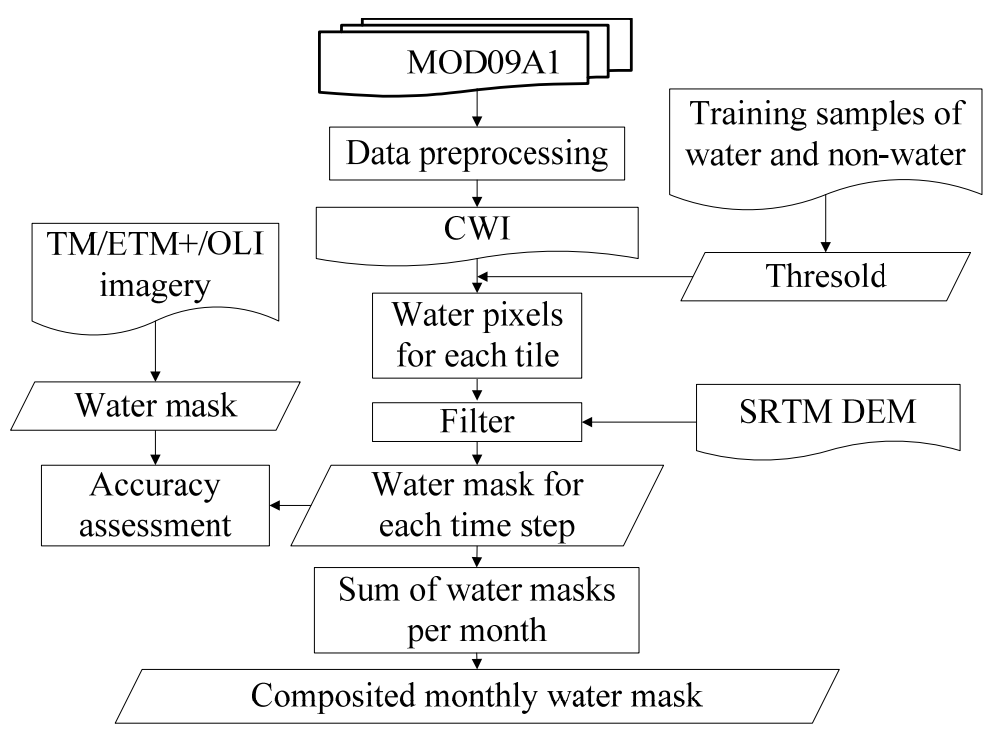

Figure 2. Workflow for water body extraction in our study.

The MODIS tiled data in Sinusoidal projection were mosaicked, re-projected using the nearest neighbor re-sampling method, and saved as GeoTIFF format using the MODIS Reprojection Tool. The 
DEM data is resampled to the pixel size of MODIS to refine the water detection results in the following steps.

The quality assessment information of MODIS data was used to exclude pixels labeled as cloudy or snow/ice. Then CWI was calculated for each MODIS tile. The atmosphere condition, water depth, and chlorophyll content all have influence on the spectral features of water on remote sensing images. A single threshold value derived for one image might not be suitable for another. Since there is no standard threshold for the whole study period, an optimized threshold must be identified for each scene or each month. In this study, we set a different threshold for each time step and extract water pixels. For the threshold selection, the training datasets that as pixels were covered by water for all time steps were collected manually from MODIS data in July. The statistics of CWI values were calculated based on training samples. We choose two standard deviations of the mean CWI value as the threshold value and classify pixels within it as water and vice versa.

Shadows in mountainous areas can lead to confusion with water bodies. To eliminate the snow and shadow effect, a slope map was used to refine the water extent. All pixels with a slope $>1^{\circ}$ were removed from the classification result because water bodies usually have flat surfaces. In this way, misclassification of shadow in mountainous areas can be corrected. In addition, to reduce the noise caused by small and temporary water bodies in mountainous areas, we removed water bodies smaller than $4 \mathrm{~km}^{2}$ in the detection results. After these steps, a binary mask with water and non-water pixels for each time step was derived.

A binary water mask was calculated for each eight-day interval. For each month, we summed up the binary masks at four time steps. For all pixels, we obtained the number of times they were classified as water. Only pixels classified as water three out of four times in a month were marked as water [14]. In this way, composited monthly water masks were generated for April, July, and September, 2000-2014. The seasonality of each lake was calculated using the maximum/minimum ratio of area extent of one representative year for each lake [35]. Finally, combining the monthly masks for April, July, and September from 2000 to 2014, a percentage coverage layer was derived. In this layer, pixel values show the percentage of times a pixel was classified as water from 2000 to 2014 . A $100 \%$ percentage means the pixel was identified as water at all the 45 monthly masks from 2000 to 2014 .

\subsection{Accuracy Assessment}

Water extents classified from Landsat images served as our validation sources in this study. An integrated water body mapping method combining the NDVI, NDWI, NIR, and slope layers was applied [36]. The commonly used threshold method was used to calculate threshold values and segment water bodies [36]. After that, the water bodies detected from Landsat images were resampled to MODIS pixel size to perform a pixel-to-pixel comparison. Confusion matrices were calculated to represent the accuracy of the classification results [37]. Three measurements, namely user's accuracy, producer's accuracy, and overall accuracy were calculated to assess the accuracies of MODIS detection. The user's accuracy is defined as the number of correctly classified water pixels divided by the total number of classified water pixels in the MODIS detection results. The producer's accuracy is defined as the total number of correctly classified water pixels divided by the total number of water 
pixels in the Landsat detection results. Overall accuracy is defined as the sum of all correctly classified water/non-water pixels divided by the total number of validation samples.

We selected four water bodies to conduct accuracy assessment for MODIS water detection results. For each lake, Landsat data acquired in April, July, and September or the nearest month were collected for each year. The MODIS results on the nearest neighboring date were selected and compared with the Landsat interpreted results to ensure the images were consistent in acquisition time.

It is worth noting that classification error exists in the water extent mapped from Landsat data and may influence the accuracy assessment results. For the 30-m resolution Landsat images, mixed pixels of lake fringes and small water bodies contain significant spectral response from backgrounds such as grasslands and croplands. In addition, the turbidity of water can increase its response at the near-infrared band and lead to a lower NDWI value [38]. A more accurate validation exercise could be conducted based on comparison with manually collected validation samples, which is very time-consuming and was not conducted in this study.

\subsection{Data Sources of Climate and Human Activities}

We also analyzed possible drivers of lake area variations in XUAR. Specifically, annual mean temperature and annual precipitation were used as indicators of regional climate. Cropland and built-up areas were used as indicators of human activities. The monthly air temperatures and precipitations for XUAR were obtained from 55 meteorological stations (National Meteorological Information Center of China Meteorological Administration; http:/cdc.nmic.cn/home.do). Monthly values were averaged or summed (for temperature and precipitation, respectively) to acquire annual values. For each variable, annual time series graphs were plotted for the 15-year study period, 2000-2014. The linear regression method and t-test are used to estimate the changing trend and test statistical significance of the changing trends of climate data. If the $P$ value derived from the statistical analysis is less than the significance level, a significant changing trend is observed. Areas of irrigated croplands and built-up areas from 2000 to 2013 were collected from the XUAR Statistical Year Book [39].

\section{Results and Discussion}

\subsection{Intra- and Inter-Annual Dynamics of Water Bodies}

The water body mapping results of the Ebinur Lake using NDWI, MNDWI, and CWI from MODIS data were compared in Figure 3. The spectral response of water is very similar to bare lands around the lake for NDWI (Figure 3b). For MNDWI, the spectral signatures of dried-up lake and snow at the lower right of the image are identical with water pixels (Figure 3d). We applied a threshold value of zero to extract water pixels from the NDWI and MNDWI images [18]. The mapping result from NDWI shows an obvious underestimation of the lake surface area (Figure 3c). An overestimation of lake surface area is observed from the MNDWI results (Figure 3e). Comparing with water bodies extracted from NDWI and MNDWI visually, the water pixels identified from CWI have higher accuracy (Figure 3g). 

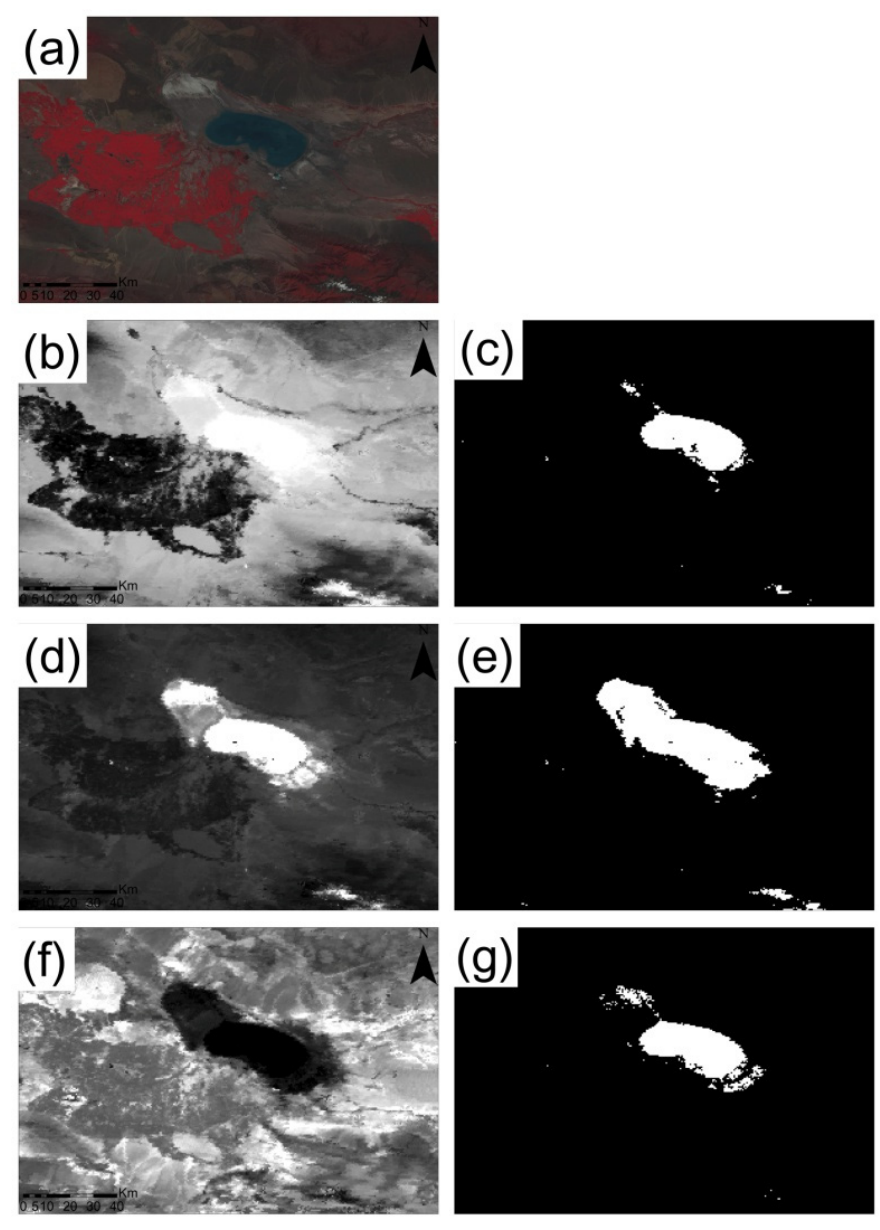

Figure 3. Water body detection results from MODIS data. (a) Landsat image; (b) NDWI [17]; (c) extracted water bodies from NDWI; (d) MNDWI [18]; (e) extracted water bodies from MNDWI; (f) CWI; and (g) extracted water bodies from CWI. Water bodies are shown in white in (c), (e), and (g).

In our study, the water body detection results from 2000 to 2014 in April, July, and September were combined and illustrated in Figure 1. In addition to the permanent water bodies that were detected at each time step, many temporal pools that were rarely mapped in global datasets were revealed. For lakes located in high elevation areas, they were frozen and cannot be detected in winter and spring months. For lakes located in arid and semi-arid areas, some of them dried up in the summer months.

We calculated the total area of 10 large lakes and analyzed their intra- and inter-annual dynamics in XUAR. Their total surface area varied from $4217 \mathrm{~km}^{2}$ (September 2010) to $5014.75 \mathrm{~km}^{2}$ (April 2003), with high seasonal variability. The largest surface area is usually in April and the smallest value in September. A decreasing trend of total lake surface area can also be observed for all three months from 2000 to 2014, even though the trend is insignificant with a 0.1 significance level (Figure 4). Significant shrinking trends were found for April (34.65 km²/year), July (22.91 km²/year), and September (31.02 $\mathrm{km}^{2} /$ year) from 2000 to 2010 with a 0.1 significance level. 


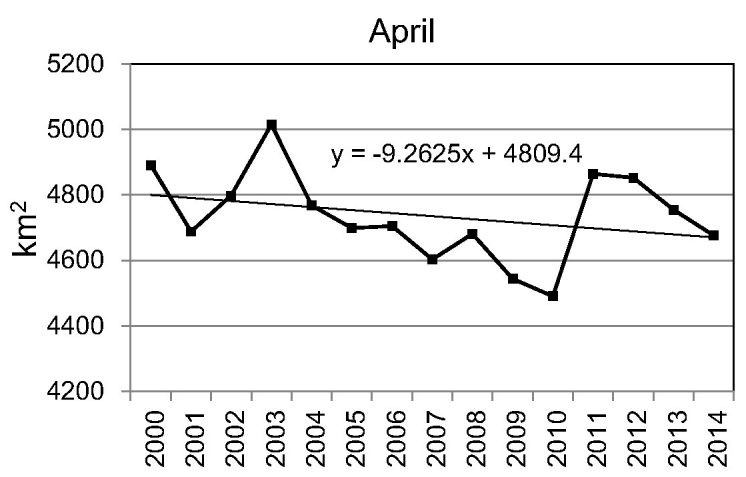

(a)

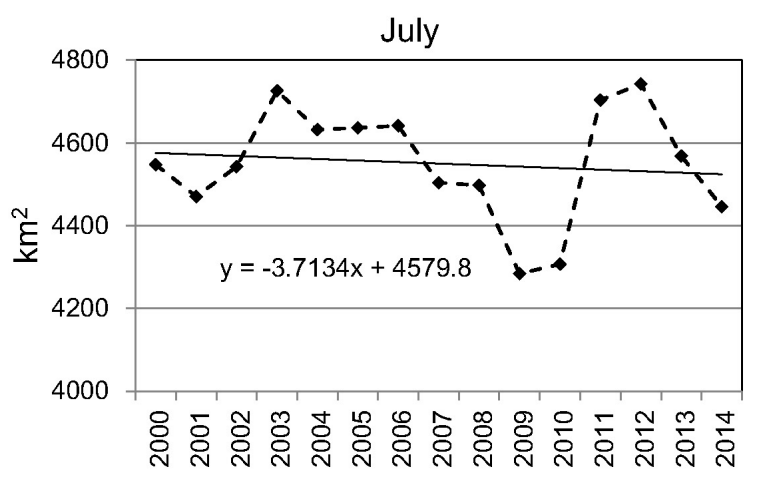

(b)

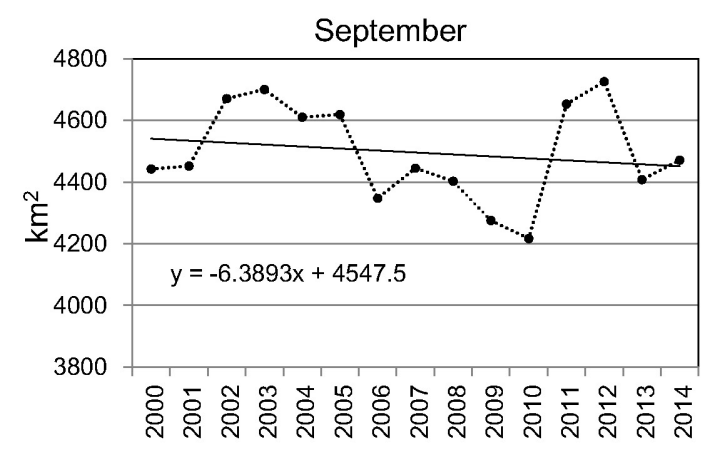

(c)

Figure 4. Inter-annual variation of the total area of major lakes for the months of (a) April; (b) July; and (c) September in XUAR from 2000 to 2014.

\subsection{Temporal Variations of Major Water Bodies}

The inter-annual variation in the surface area of each major lake was illustrated for April, July, and September (Figure 5). The changing trend in the surface area of each lake in July was calculated (Figure 6). The statistics of inter-annual variations of surface area for each lake were listed in Table 3. These results revealed that the lakes along the Tianshan Mountains (central Xinjiang) are shrinking, while the lakes in the northern and southern parts are expanding. This may indicate that human activities cause the lake to shrink, since most human settlements and agricultural lands are distributed along the Tianshan Mountains (Figure 6). Lakes where there is less human influence exhibited expanding trends, mainly due to changes in climate variables. 


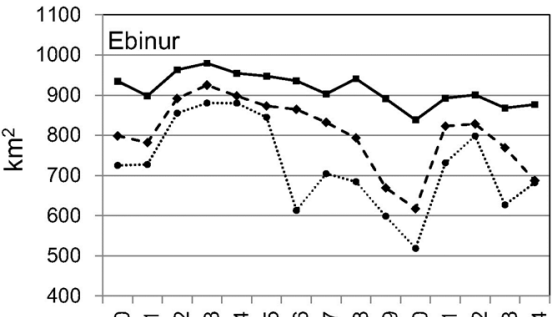

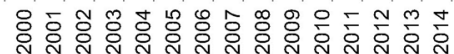

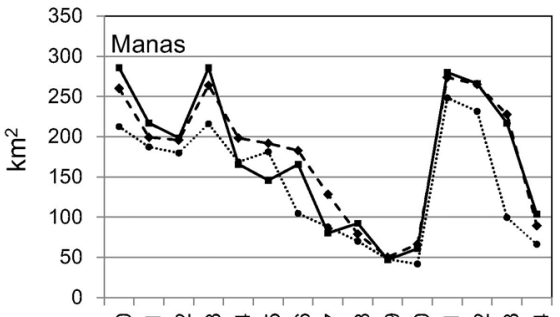

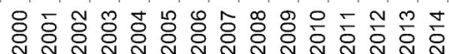

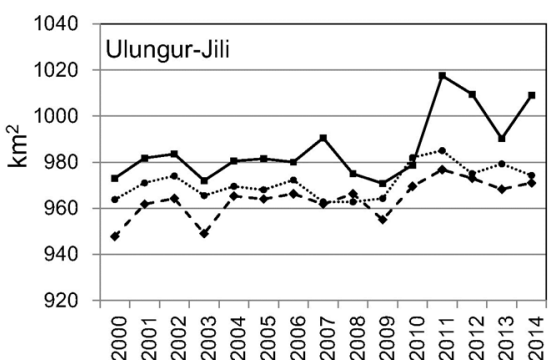

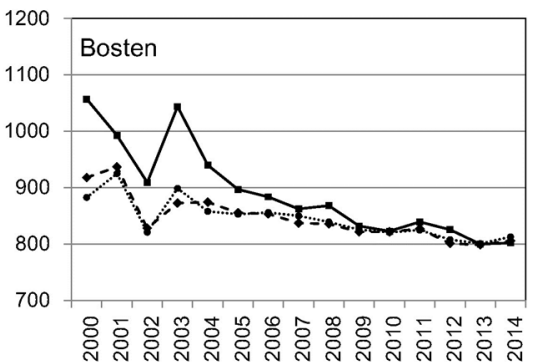
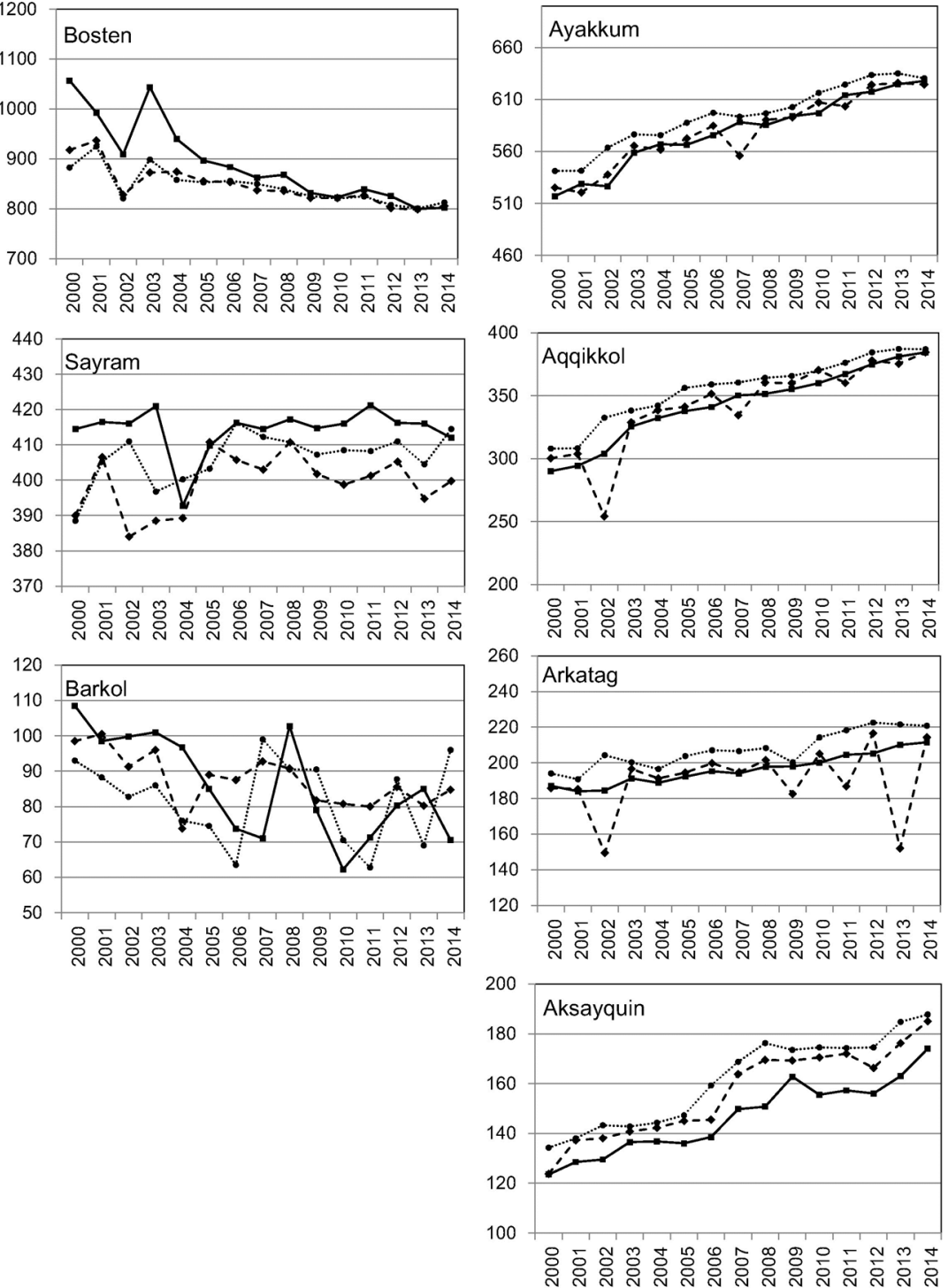

Figure 5. Inter-annual variation in the surface area of major lakes for the months of April, July, and September in XUAR from 2000 to 2014. Solid, dashed, and dotted lines represent April, July, and September, respectively.

Table 3. Changing trend in the surface area of major lakes in XUAR from 2000 to 2014.

\begin{tabular}{ccccc}
\hline Name & April & July & September & Seasonality (max/min ratio) \\
\hline Ebinur & -6.09 & -10.36 & -11.74 & 1.29 \\
Manas & -5.53 & -5.08 & -6.59 & 1.52 \\
Ulungur-Jili & 2.08 & 1.25 & 0.81 & 1.03 \\
Bosten & -16.71 & -7.78 & -6.36 & 1.06 \\
Sayram & 0.22 & 0.61 & 0.90 & 1.03 \\
Barkol & -2.32 & -1.07 & -0.43 & 1.38 \\
Ayakkum & 7.80 & 7.48 & 6.72 & 1.05 \\
Aqqikkol & 6.55 & 6.82 & 5.52 & 1.06 \\
Arkatag & 1.9 & 1.13 & 2.08 & 1.04 \\
Aksayquin & 3.21 & 3.88 & 3.92 & 1.15 \\
\hline
\end{tabular}

Note: The values in bold indicate significant trends ( $p$ value $<0.1$ ). 


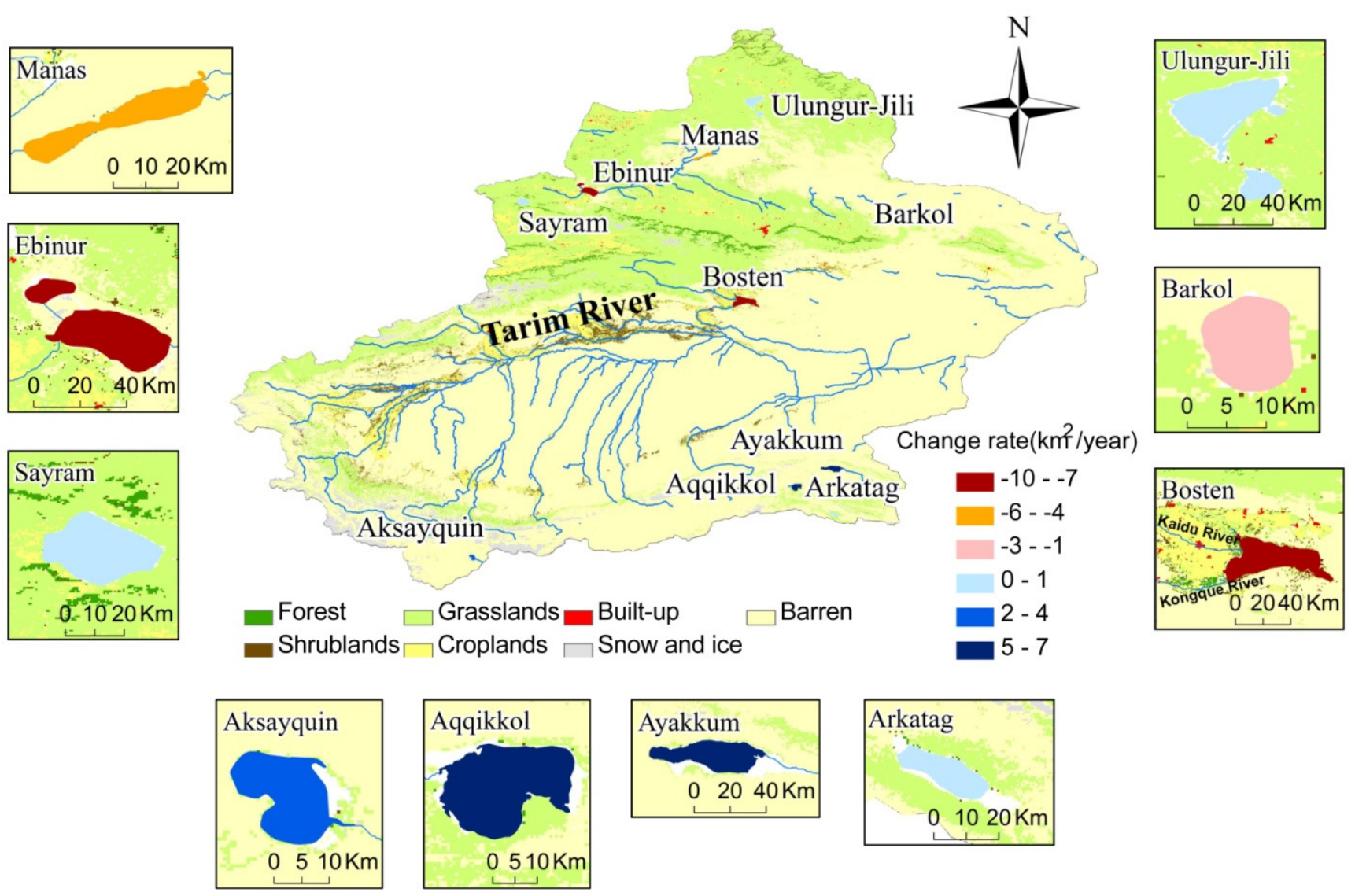

Figure 6. Changing trends and rates in the surface area of major lakes in XUAR in July from 2001 to 2014. Spatial distribution of land cover/use types was extracted from MODIS land cover type product in 2012 [33].

The highest seasonality is at Manas Lake, Barkol Lake, and Ebinur Lake. The lowest seasonality exists at Ulungur-Jili Lake, Sayram Lake, and Arkatag Lake. The seasonal dynamics of Ebinur Lake, Manas Lake, Barkol Lake, and Aksayquin Lake, which have the highest seasonality, are illustrated in Figure 7. For each pixel, we summed the number of times it was classified as water for April, July, and September over the entire study period. The monthly composite was classified into four intervals to indicate areas that stayed stable over the entire time series, and areas that were covered by water for several years during the 2000-2014 period. Different seasonal behaviors were observed for the four lakes. Ebinur Lake showed the largest area in April and the smallest in September. Manas Lake was largest in July and smallest in September. 

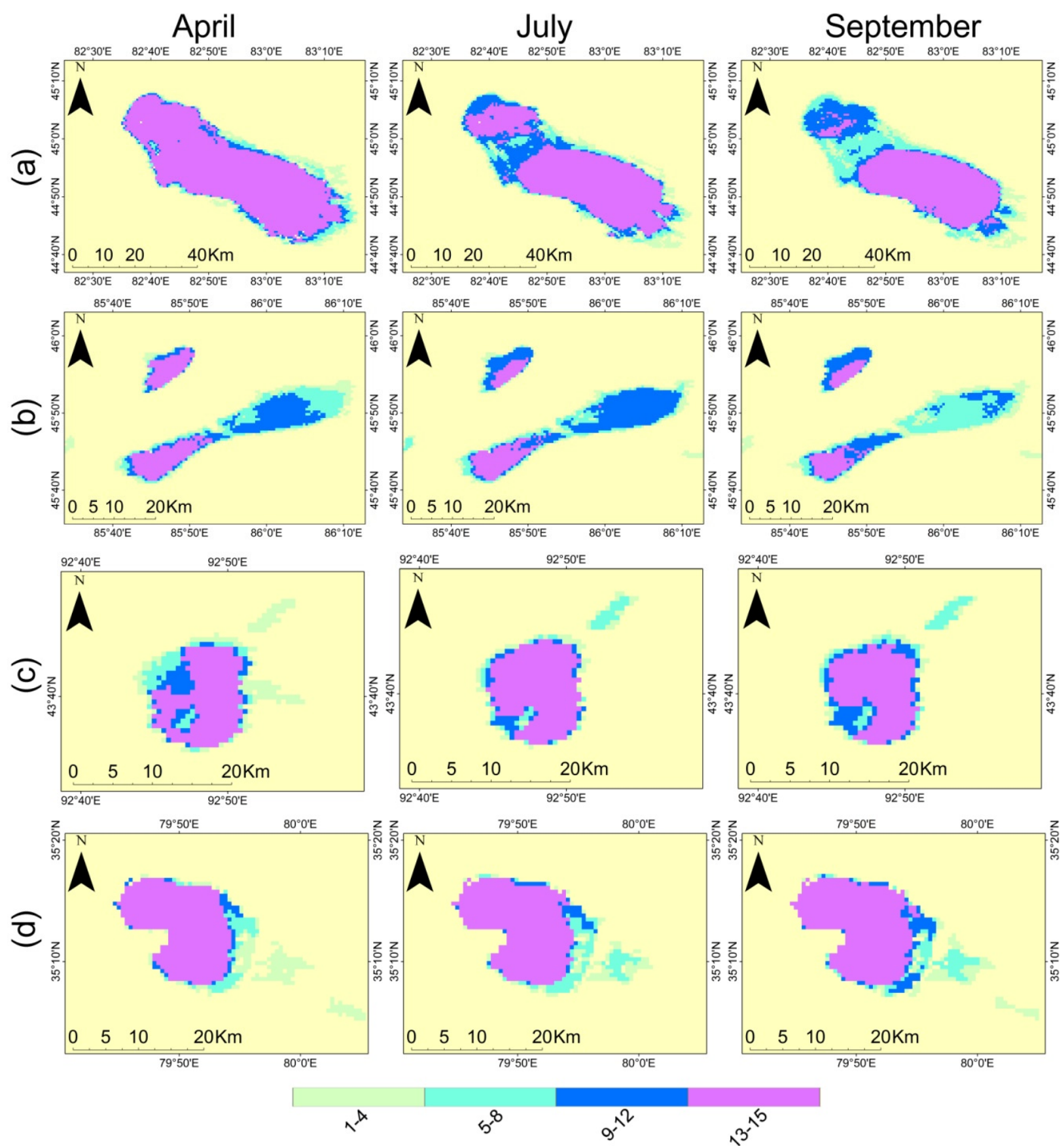

Figure 7. Typical seasonal water bodies of XUAR and their temporal dynamics for the months of April, July, and September from 2000 to 2014. (a) Ebinur; (b) Manas; (c) Barkol and (d) Aksayquin Lakes. The numbers at each pixel indicate the number of times it was detected as a water body during the 2000-2014 period.

\subsection{Accuracy Assessment}

Figure 8 illustrates the comparison of a monthly water mask derived from MODIS data with a water mask derived from Landsat images of the same month. The small water bodies that were detected from Landsat data cannot be extracted from MODIS imagery at $500 \mathrm{~m}$ resolution. This leads to a partial disagreement of detection results between Landsat and MODIS data. Based on our assessment, an overall accuracy of 0.97 is obtained (Table 4), which is adequate for the dynamic analysis of lake 
surface area. The detection results for Manas Lake showed lower user accuracy than the other lakes. Due to the high concentration of salts and other dissolved minerals, the spectral feature of water in Manas Lake is different from other water bodies. Therefore, the identification of water pixels using a general threshold for all of the water bodies in the entire study area may lead to misclassifications. For Bosten Lake, mixed pixels of wetland and small water bodies can be misclassified as non-water bodies due to the coarse resolution of MODIS data. The lake ice and snow can also lead to lower accuracies in April for plateau lakes like Ayakkum.
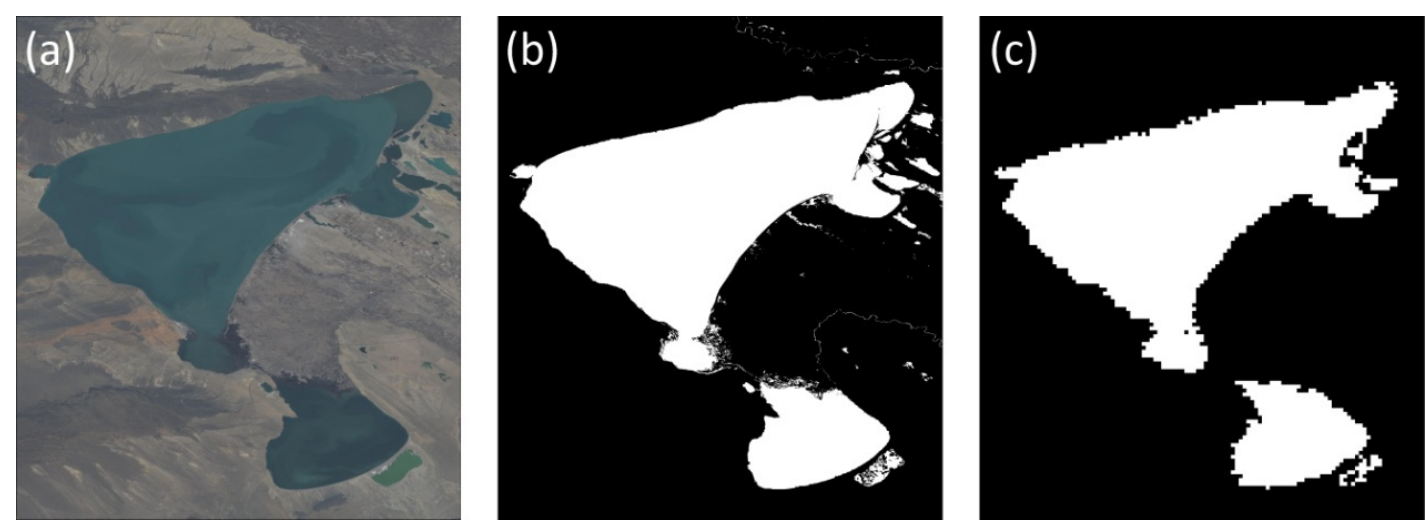

Figure 8. Comparison of a water body derived from MODIS data and Landsat for April 2014, Ulungur Lake. (a) Landsat image; (b) water mask derived from Landsat data; and (c) water mask derived from MODIS data.

Table 4. The error matrix, overall, producer's, and user's accuracies of water bodies and non-water bodies resulting from MODIS time series data, 2000-2014.

\begin{tabular}{ccccccccc}
\hline \multirow{2}{*}{ Month } & \multicolumn{2}{c}{ Ulungur } & \multicolumn{2}{c}{ Manas } & \multicolumn{2}{c}{ Bosten } & \multicolumn{2}{c}{ Ayakkum } \\
\cline { 2 - 9 } & User & Prod & User & Prod & User & Prod & User & Prod \\
\hline April & 0.92 & 0.93 & 0.72 & 0.97 & 0.95 & 0.89 & 0.97 & 0.95 \\
July & 0.96 & 0.92 & 0.66 & 0.95 & 0.99 & 0.86 & 0.95 & 0.94 \\
September & 0.97 & 0.93 & 0.63 & 0.93 & 0.99 & 0.89 & 0.97 & 0.97 \\
\hline Overall Accuracy & \multicolumn{4}{c}{0.97} \\
\hline
\end{tabular}

\subsection{Effects of Regional Climate and Human Activities on Lake Changes}

The linear trend of temperature and precipitation are not statistically significant at the 0.1 significance level for 2000-2014. In our study period, an increase in precipitation occurred in 2010, which corresponds well to the extending lake area in 2011 and 2012 (Figure 9). The area of cropland increased from 3.39 million hectares in 2000 to 5.21 million hectares in 2013. Built-up areas increased from $473 \mathrm{~km}^{2}$ in 2000 to $1065 \mathrm{~km}^{2}$ in 2013. As we can see in Figure 5, the oases comprised of agricultural lands and built-up areas are distributed in river plains near major lakes. The water demands of oases can influence aerial changes in lakes that have river runoff as their main inflows, such as Ebinur, Bosten, and Manas Lakes. For a regional comparison, the changing trends of temperature and precipitation at meteorological stations near each major lake were analyzed (Table 5). Their relationships with lake area changes were also analyzed. Due to the lack of observed climate data, the analysis was not performed for the four plateau lakes. 

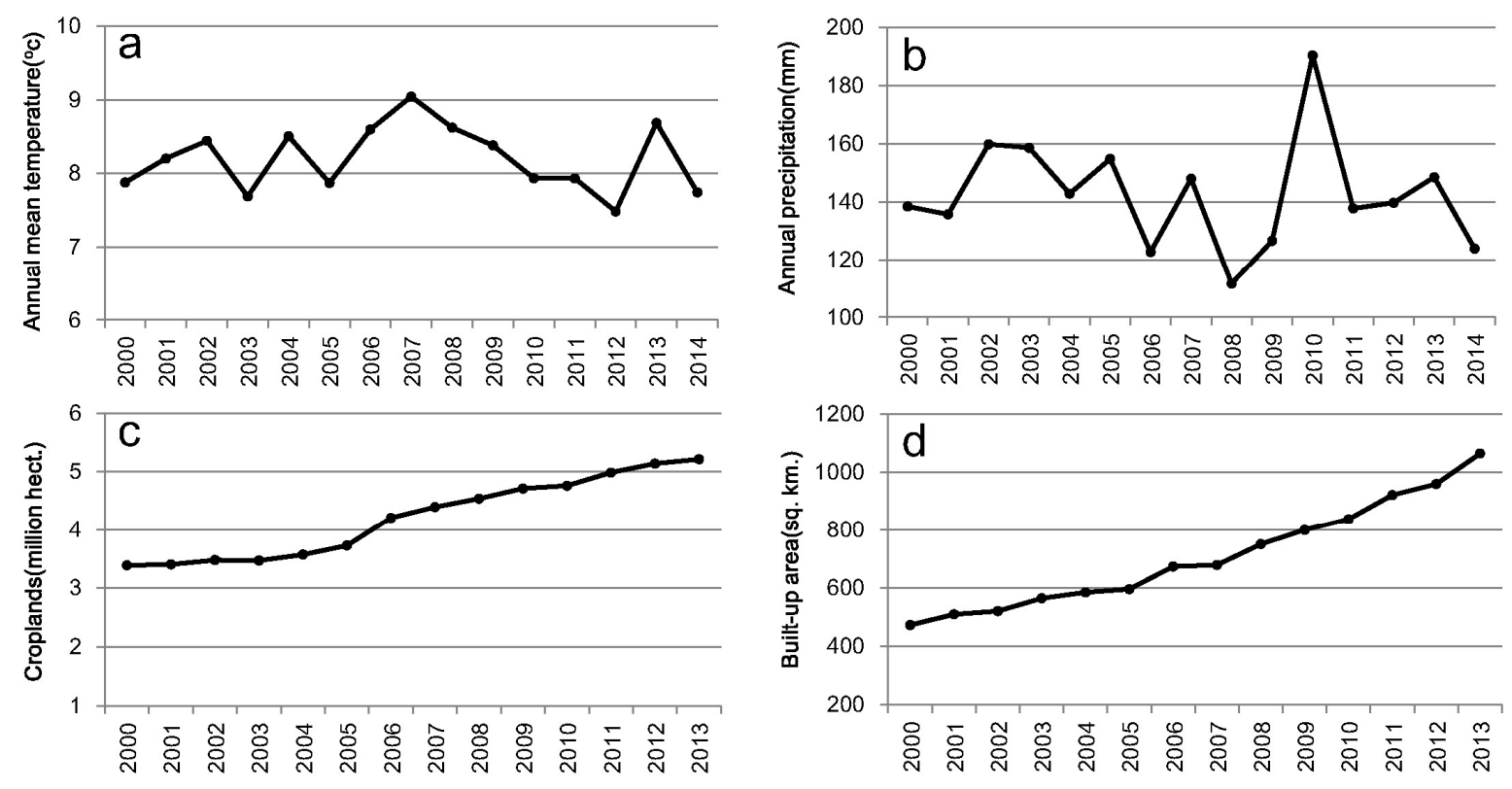

Figure 9. Variations in (a) annual mean temperature; (b) annual precipitation; (c) area of croplands; and (d) built-up areas in XUAR over the study period.

Table 5. Changing trends in temperature and precipitation at meteorological stations near the major lakes from 2000 to 2014.

\begin{tabular}{ccccccc}
\hline Climate Variable & Ebinur & Manas & Ulungur-Jili & Bosten & Sayram & Barkol \\
\hline Annual Mean Temperature $\left({ }^{\circ} \mathbf{C}\right)$ & -0.20 & -0.06 & 0.31 & -0.26 & -0.27 & 0.51 \\
Annual Precipitation (mm) & -0.28 & -1.70 & -2.28 & -2.72 & -3.21 & 2.82 \\
\hline
\end{tabular}

Among the major lakes, three plain lake or lake systems, Ebinur, Manas, and Ulungur-Jili, were analyzed. Located in low elevation plain areas, their main supply is river runoff, which can be influenced tremendously by human activities. Ebinur is the largest saline lake in XUAR. With a maximum depth of $3.5 \mathrm{~m}$ and a mean depth of $1.2 \mathrm{~m}$, it is a closed lake without outlet. Its hydrologic input is mainly from the Bo and Jing rivers, which originate from precipitation in mountainous areas. In their analysis of multi-temporal VGT-S10 data from 1 April 1998 to 31 December 2005, Ma et al. (2007) revealed that this lake had a peak area of $903 \mathrm{~km}^{2}$ in 2003 and subsequently decreased to an area of $847 \mathrm{~km}^{2}$ in 2004 [23]. Our study showed a decreasing trend of surface area from 2000 to 2014 in all three seasons, with a short increase in 2002-2004 (Figure 5). The significant decreasing trend of the Ebinur Lake is $6.09 \mathrm{~km}^{2} /$ year for April, $10.36 \mathrm{~km}^{2} /$ year for July, and $11.74 \mathrm{~km}^{2} /$ year for September, respectively. A slight decreasing trend of precipitation and temperature was revealed (Table 5). According to Zhang et al. (2015), human factors, such as population growth and agricultural development, led to the increase in desertification area in the Ebinur Lake region between 1990 and 2010 [40].

Manas Lake is the terminal lake of Manas River. This lake is about $55 \mathrm{~km}$ long and 15-20 km wide, with an area of about $550 \mathrm{~km}^{2}$ and an average depth $6 \mathrm{~m}$ [41]. Our results show a decreasing trend of Manas Lake from 2000 to 2014. The smallest lake size occurred in 2009 and 2010 (Figure 5). A decreasing trend of precipitation and temperature was observed at the meteorological station near Manas Lake (Table 5). Manas River Valley is a representative area for oasis exploitation in Xinjiang as a primary agricultural production region and core region of economic development of the northern 
slope of the Tianshan [41]. The expansion of oasis in Manas River Valley was characterized by the spread of settlements and agricultural lands. In addition to reclaiming agricultural lands, many hydrological constructions, including reservoirs, wells, and canals, were built along the Manas River for irrigation of the croplands.

Ulungur-Jili lake system is a closed inland lake, with its water supplied by the Ulungur River, groundwater, precipitation, and snow melting. As the second largest lake in XUAR, the Ulungur-Jili lake system can be divided into two sections, the Ulungur Lake and the smaller Jili Lake, connected by a narrow channel. In 2011, Ulungur Lake had an average depth of $10.4 \mathrm{~m}$ and a surface area of $859 \mathrm{~km}^{2}$, and Jili Lake had an average depth of $8.8 \mathrm{~m}$ and an area of $169 \mathrm{~km}^{2}$ [42]. Based on an analysis of the lake area with Landsat images acquired in August, a stable or slightly increasing trend of lake surface area is revealed from 2000 to 2011 [43]. A slight extending trend of Ulungur-Jili Lake was also observed in our study from 2000 to 2014. Increasing temperature and decreasing precipitation were observed at the nearby meteorological stations. Since snow and ice melting off the Altay Mountain is the main runoff supply of Irtysh River, snow and glacier changes caused by the increasing temperature contributed to the variation of lake area of the Ulungur-Jili lake system.

Bosten Lake, as a transition lake located between the mountains and plains, is the largest inland freshwater lake in China. As an open catchment lake with outlets, Bosten Lake lies at the end of Kaidu River and the beginning of Kongque River. The lake inflow mainly comes from Kaidu River, which contributes about $95 \%$ of the total water inflow [44,45]. The main outflow is Kongque River and evaporation [46]. With a large area in 2001 and 2003 (Figure 5), our study revealed an obvious decreasing trend in the surface area of Bosten Lake from 2000 to 2014. The nearby meteorological station observed the decreasing trend of precipitation and temperature. According to the monthly mean lake level data, the lake level decreased dramatically from 2002 to 2010 [46]. The sharply decreasing lake level during 2003 to 2010 was reported to be caused by the emergency project of transferring water to Tarim River and increasing lake outflow in addition to the reduced precipitation [46].

Sayram Lake is the largest and highest alpine lake in XUAR. The lake is located in a mountain basin in the western part of the Tian Shan with an average water depth of $46.1 \mathrm{~m}$. It has a frozen period extending for six months from October to May [47]. Though a decreasing trend of precipitation and temperature was observed at the nearby meteorological station, a slight increasing trend was observed from 2000 to 2014 in our study. Located in a natural environment, Sayram Lake was less impacted by anthropogenic disturbances and showed a stable surface area from 1975 to 2007 [22].

Barkol Lake is a closed saline lake with an elevation of about $1580 \mathrm{~m}$. Located in the Barkol Basin, Barkol Lake is bordered by the Barkol Range, the eastern Tianshan to the south, and the Moqinwula Range to the north. The average water depth is only $0.6 \mathrm{~m}$, with a maximum water depth of about $1 \mathrm{~m}$ [48]. In our study, a shrinking trend of water surface area was observed from 2000 to 2014, while an increasing trend of precipitation was observed (Table 5). The primary cause for lake size decrease may be attributed to human interference. Due to the mirabilite production and reducing precipitation near the lake, the lake area shrunk from $233 \mathrm{~km}^{2}$ in the $1950 \mathrm{~s}$ to $60 \mathrm{~km}^{2}$ in 2011 [49]. The severe mineralization of lake water led to large area degradation of the surrounding wetlands [49].

Ayakkum, Aqqikkol, and Arkatag Lakes are located in the Kumkol Basin between the Altyn Mountains and the Kunlun Mountains. Aksayquin Lake is located in the western Kunlun Mountains of the northern Tibetan Plateau. The main supply of the four lakes is river runoff from the melting of 
glaciers and snow. In our study, significant expanding trends were observed for these four lakes from 2000 to 2014 except Arkatag Lake in July. Based on Landsat image analysis over the entire Tibetan Plateau, Aqqikkol had undergone surface extent increases in excess of 10\% from 2000 to 2011 [8]. The expansion of lake areas and increasing trend of lake level on northern Tibetan Plateau was observed and documented by several studies [8,50,51]. Due to the increasing temperature, the water recharge increased a lot from accelerated melting of glaciers and perennial snow cover [52], and permafrost degradation $[53,54]$. However, for areas where surface water resources are generated mainly in the mountain glaciers of XUAR, the increasing flows caused by melting of mountain glaciers cannot be sustained in the long term if the glaciers disappear due to increasing temperature [55].

\section{Conclusions}

This study presented a time series analysis of lake water surfaces across XUAR using MODIS data from 2000 to 2014. A classification approach based on water index calculation and dynamic threshold selection was developed. Compositing water detection results of each time step, water masks were derived for the months of April, July, and September. The major lakes with an area of $>100 \mathrm{~km}^{2}$ were categorized into four classes based on their topographic locations. The seasonal and inter-annual surface area variation of the 10 major lakes was revealed in detail.

For plain lakes, the surface area of Ebinur Lake showed a significant shrinking trend and Manas lake an insignificant shrinking trend. They are both influenced by the expanding oasis and increasing water consumption. The Ulungur-Jili Lake had a stable area throughout the entire time period. The decreasing area of Bosten Lake may have been caused by the construction of hydrological projects in addition to the reduced precipitation. For mountain lakes, overexploitation has caused the shrinking of the Barkol Lake and the degradation of surrounding wetlands. As the largest and highest alpine lake, Sayram Lake showed a significant expanding trend in September. The four plateau lakes exhibited significant expanding trends for all three seasons except Arkatag Lake in July.

The lake dynamics revealed by MODIS time series are useful for ecological assessment of XUAR. Further studies are needed to use satellite imagery with different spatiotemporal resolutions, such as AVHRR and Landsat data since the 1970-80s, to capture the long-term dynamics of lakes in XUAR. It is also important to integrate the analysis of satellite data and climatic datasets for better understanding of the impact of climate change on water bodies in this arid and semi-arid region.

\section{Acknowledgments}

This research was supported by the National Natural Science Foundation of China under Grant No. 41471369, the Open Research Fund of State Key Laboratory of Remote Sensing Science under Grant No. OFSLRSS201413, and the Major International Cooperation and Exchange Project "Comparative study on global environmental change using remote sensing technology" under Grant No. 4112011400. The authors appreciate the financial assistance provided by the China Scholarship Council. 


\section{Author Contributions}

Yingkui Li and Cuizhen Wang designed the research. Qingting Li and Linlin Lu conducted the water body detection and dynamic analysis. Yue Sui collected the MODIS data and performed quality assessment. All authors interpreted and reviewed the data. Qingting Li, Linlin Lu, Cuizhen Wang, and Yingkui Li wrote the final manuscript.

\section{Conflicts of Interest}

The authors declare no conflict of interest.

\section{References}

1. Oki, T.; Shinjiro, K. Global hydrological cycles and world water resources. Science 2006, 313, 1068-1072.

2. Soti, V.; Tran, A.; Bailly, J.S.; Puech, C.; Seen, D.L.; Bégué, A. Assessing optical earth observation systems for mapping and monitoring temporary ponds in arid areas. Int. J. Appl. Earth Obs. 2009, 11, 344-351.

3. Haas, E.M.; Bartholomé, E.; Lambin, E.F.; Vanacker, V. Remotely sensed surface water extent as an indicator of short-term changes in ecohydrological processes in sub-Saharan Western Africa. Remote Sens. Environ. 2011, 115, 3436-3445.

4. Haas, E.M.; Bartholomé, E.; Combal, B. Time series analysis of optical remote sensing data for the mapping of temporary surface water bodies in sub-Saharan western Africa. J. Hydrol. 2009, 370, 52-63.

5. Lehner, B.; Doll, P. Development and validation of a global database of lakes, reservoirs and wetlands. J. Hydrol. 2004, 296, 1-22.

6. Vector Map Level 0 (VMap0). Available online: http://earth-info.nga.mil/publications/vmap0.html (accessed on 16 February 2015).

7. Li, W.; Du, Z.; Ling, F.; Zhou, D.; Wang, H.; Gui, Y.; Sun, B.; Zhang, X. A comparison of land surface water mapping using the normalized difference water index from TM, ETM+ and ALI. Remote Sens. 2013, 5, 5530-5549.

8. Song, C.; Huang, B.; Ke, L. Modeling and analysis of lake water storage changes on the Tibetan Plateau using multi-mission satellite data. Remote Sens. Environ. 2013, 135, 25-35.

9. Fujita, K.; Sakai, A.; Nuimura, T.; Ymaguchi, S.; Sharma, R.R. Recent changes in Imja Glacial Lake and its damming moraine in the Nepal Himalaya revealed by in situ surveys and multi-temporal ASTER imagery. Environ. Res. Lett. 2009, 4, doi:10.1088/1748-9326/4/4/045205.

10. Lira, J. Segmentation and morphology of open water bodies from multispectral images. Int. J. Remote Sens. 2006, 27, 4015-4038.

11. Lacaux, J.P.; Tourre, Y.M.; Vignolles, C.; Ndione, J.A.; Lafaye, M. Classification of ponds from high-spatial resolution remote sensing: Application to rift valley fever epidemics in Senegal. Remote Sens. Environ. 2007, 106, 66-74.

12. Chipman, J.W.; Lillesand, T.M. Satellite-based assessment of the dynamics of new lakes in southern Egypt. Int. J. Remote Sens. 2007, 28, 4365-4379. 
13. Sun, F.; Zhao, Y.; Gong, P.; Ma, R.; Dai, Y. Monitoring dynamic changes of global land cover types: Fluctuations of major lakes in China every 8 days during 2000-2010. Chin. Sci. Bull. 2014, 59, 171-189.

14. Klein, I.; Dietz, A.J.; Gessner, U.; Galayeva, A.; Myrzakhmetov, A.; Kuenzer, C. Evaluation of seasonal water body extents in Central Asia over the past 27 years derived from medium-resolution remote sensing data. Int. J. Appl. Earth Obs. 2014, 26, 335-349.

15. Deus, D.; Gloaguen, R. Remote sensing analysis of lake dynamics in semi-arid regions: Implication for water resource management. Lake Manyara, East African Rift, Northern Tanzania. Water 2013, 5, 698-727.

16. Wang, J.; Sheng, Y.; Tong, T.S.D. Monitoring decadal lake dynamics across the Yangtze Basin downstream of Three Gorges Dam. Remote Sens. Environ. 2014, 152, 251-269.

17. Mcfeeters, S.K. The use of normalized difference water index (NDWI) in the delineation of open water features. Int. J. Remote Sens. 1996, 17, 1425-1432.

18. $\mathrm{Xu}, \mathrm{H}$. Modification of normalized difference water index (NDWI) to enhance open water features in remotely sensed imagery. Int. J. Remote Sens. 2006, 27, 3025-3033.

19. Mo, W.; Sun, H.; Zhong, S.; Huang, Y.; He, L. Research on the CIWI model and its application. Remote Sens. Inf. 2007, 5, 16-21.

20. Song, C.; Huang, B.; Ke, L.; Richards, K.S. Remote sensing of alpine lake water environment changes on the Tibetan Plateau and surroundings: A review. ISPRS J. Photogramm. Remote Sens. 2014, 92, 26-37.

21. Chinese Academy of Forestry. The List of National Nature Reserve in China. 2013. Available online: http://www.papc.cn/ (accessed on 16 August 2015).

22. Bai, J.; Chen, X.; Li, J.; Yang, L.; Fang, H. Changes in the area of inland lakes in arid regions of central Asia during the past 30 years. Environ. Monit. Assess. 2011, 178, 247-256.

23. Ma, M. Change in area of Ebinur Lake during the 1998-2005 period. Int. J. Remote Sens. 2007, $28,5523-5533$.

24. Ma, R.; Duan, H.; Hu, C.; Feng, X.; Li, A.; Ju, W. A half-century of changes in China's lakes: Global warming or human influence? Geophys. Res. Lett. 2010, 37, doi:10.1029/2010GL045514.

25. Yang, X.K; Lu, X.X. Drastic change in China's lakes and reservoirs over the past decades. Sci. Rep. 2014, 4, doi:10.1038/srep06041.

26. Bai, R.; He, L.; Wu, J. Analysis on recent change of water area of the main lakes in Xinjiang based on MODIS data. Arid Zone Res. 2012, 29, 561-566.

27. Wang, T.; Yan, C.Z.; Song, X.; Xie, J.L. Monitoring recent trends in the area of Aeolian desertified land using Landsat images in China's Xinjiang region. ISPRS J. Photogramm. Remote Sens. 2012, 68, 184-190.

28. Lu, L.; Kuenzer, C.; Wang, C.; Guo, H.; Li, Q. Evaluation of three MODIS-derived vegetation index time series for dryland vegetation dynamics monitoring. Remote Sens. 2015, 7, 7597-7614.

29. Vermote, E.F.; Kotchenova, S.Y.; Ray, J.P. MODIS surface reflectance user's guide. Available online: http://modis-sr.ltdri.org/guide/MOD09_UserGuide_v1_3.pdf (accessed on 16 August 2015).

30. Huang, S.; Li, J.; Xu, M. Water surface variations monitoring and flood hazard analysis in Dongting Lake area using long-term Terra/MODIS data time series. Nat. Hazards 2012, 62, 93-100. 
31. Caroll, M.L.; Townshend, J.R.; DiMiceli, C.W.; Noojipady, P.; Sohlberg, R.A. A new global raster water mask at $250 \mathrm{~m}$ resolution. Int. J. Digit. Earth 2009, 2, 291-308.

32. Huesler, F.; Jonas, T.; Wunderle, S.; Albrecht, S. Validation of a modified snow cover retrieval algorithm from historical 1-km AVHRR data over the European Alps. Remote Sens. Environ. 2012, 121, 497-515.

33. Friedl, M.A.; Sulla-Menashe, D.; Tan, B.; Schneider, A.; Ramankutty, N.; Sibley, A.; Huang, X. MODIS Collection 5 global land cover: Algorithm refinements and characterization of new datasets. Remote Sens. Environ. 2010, 114, 168-182.

34. Lu, L.; Kuenzer, C.; Guo, H.; Li, Q.; Long, T.; Li, X. A novel land cover classification map based on a MODIS time-series in Xinjiang, China. Remote Sens. 2014, 6, 3387-3408.

35. Feng, L.; Hu, C.; Chen, X.; Cai, X.; Tian, L.; Gan, W. Assessment of inundation changes of Poyang Lake using MODIS observations between 2000 and 2010. Remote Sens. Environ. 2012, 121, 80-92.

36. Lu, S.; Wu, B.; Yan, N.; Wang, H. Water body mapping method with HJ-1A/B satellite imagery. Int. J. Appl. Earth Obs. 2011, 13, 428-434.

37. Congalton, R.G.; Green, K. Assessing the Accuracy of Remotely Sensed Data: Principles and Practices, 2nd ed.; CRC Press: Boca Raton, FL, USA, 2009.

38. Frazier, P.S.; Page, K.J. Water body detection and delineation with Landsat TM data. Photogramm. Remote Sens. 2000, 66, 1461-1467.

39. Xinjiang Uygur Autonomous Region Bureau of Statistics. Xinjiang Uygur Autonomous Region Statistical Yearbook; China Statistics Press: Beijing, China, 2001-2014.

40. Zhang, F.; Tiyip, T.; Johnson, V.C.; Kung, H.; Ding, J.; Zhou, M.; Fan, Y.; Kelimu, A.; Nurmuhammat, I. Evaluation of land desertification from 1990 to 2010 and its causes in Ebinur Lake region, Xinjiang China. Environ. Earth Sci. 2015, 73, 5731-5745.

41. Cheng, W.; Zhou, C.; Liu, H.; Zhang, Y.; Jiang, Y.; Zhang, Y.; Yao, Y. The oasis expansion and eco-environment change over the last 50 years in Manas River Valley, Xinjiang. Sci. China Ser. D 2006, 49, 163-175.

42. Wu, J.; Zeng, H.; Ma, L.; Bai, R. Recent changes of selected lake water resources in arid Xinjiang, northwestern China. Quat. Sci. 2012, 32, 142-150.

43. Maitiniyazi, A.; Kasimu, A. Change trend of surface water resources in Altai, Xinjiang China. J. Desert Res. 2014, 34, 1393-1401.

44. Gao, H.; Yao, Y. Quantitative effect of human activities on water level change of Bosten Lake in recent 50 years. Sci. Geogr. Sin. 2005, 25, 305-309.

45. Liu, L.; Zhao, J.; Zhang, J.; Peng, W.; Fan, J.; Zhang, T. Water balance of Lake Bosten using annual water-budget method for the past 50 years. Arid Land Geogr. 2013, 36, 33-40.

46. Guo, M.; Wu, W.; Zhou, X.; Chen, Y.; Li, J. Investigation of the dramatic changes in lake level of the Bosten Lake in northwestern China. Theor. Appl. Climatol. 2015, 119, 341-351.

47. Ma, D.; Zhang, L.; Wang, Q.; Zeng, Q.; Jiang, F.; Wang, Y.; Hu, R. Influence of warm-wet climate on Sailimu Lake. J. Glaciol. Geocryol. 2003, 25, 219-223.

48. Xue, J.; Zhong, W. Holocene climate variation denoted by Barkol lake sediments in northeastern Xinjiang and its possible linkage to the high and low latitude climates. Sci. China Earth Sci. 2011, $54,603-614$. 
49. Zheng, S.; Luo, L. Variation of water quality in Balikun Lake in the last 18 years and water resource protection strategies. Environ. Sci. Tech. 2011, 34, 85-88.

50. Zhang, G.; Xie, H.; Kang, S.; Yi, D.; Ackley, S.F. Monitoring lake level changes on the Tibetan Plateau using ICESat altimetry data (2003-2009). Remote Sens. Environ. 2011, 115, 1733-1742.

51. Liao, J.; Shen, G.; Li, Y. Lake variations in response to climate change in the Tibetan Plateau in the past 40 years. Int. J. Digit. Earth 2013, 6, 534-549.

52. Yao, T.; Pu, J.; Lu, A.; Wang, Y.; Yu, W. Recent glacial retreat and its impact on hydrological processes on the Tibetan Plateau, China, and surrounding regions. Arct. Antarct. Alp. Res. 2007, 39, 642-650.

53. Cheng, G.; $\mathrm{Wu}, \mathrm{T}$. Responses of permafrost to climate change and their environmental significance, Qinghai-Tibet Plateau. J. Geophys. Res. 2007, 112, doi:10.1029/2006JF000631.

54. Li, Y.; Liao, J.; Guo, H.; Liu, Z.; Shen, G. Patterns and potential drivers of dramatic changes in Tibetan lakes, 1972-2010. PLoS ONE 2014, 9, doi:10.1016/j.jaridenv.2009.04.022.

55. Lioubimtseva, E.; Henebry, G.M. Climate and environmental change in arid Central Asia: Impacts, vulnerability, and adaptations. J. Arid Environ. 2009, 73, 963-977.

(C) 2015 by the authors; licensee MDPI, Basel, Switzerland. This article is an open access article distributed under the terms and conditions of the Creative Commons Attribution license (http://creativecommons.org/licenses/by/4.0/). 